\title{
Visual Search among Items of Different Salience: Removal of Visual Attention Mimics a Lesion in Extrastriate Area V4
}

\author{
Jochen Braun \\ California Institute of Technology, Division of Biology, Pasadena, California 91125
}

In more than one respect, visual search for the most salient or the least salient item in a display are different kinds of visual tasks. The present work investigated whether this difference is primarily one of perceptual difficulty, or whether it is more fundamental and relates to visual attention. Display items of different salience were produced by varying either size, contrast, color saturation, or pattern. Perceptual masking was employed and, on average, mask onset was delayed longer in search for the least salient item than in search for the most salient item. As a result, the two types of visual search presented comparable perceptual difficulty, as judged by psychophysical measures of performance, effective stimulus contrast, and stability of decision criterion. To investigate the role of attention in the two types of search, observers attempted to carry out a letter discrimination and a search task concurrently. To discriminate the letters, observers had to direct visual attention at the center of the display and, thus, leave unattended the periphery, which contained target and distractors of the search task. In this situation, visual search for the least salient item was severely impaired while visual search for the most salient item was only moderately affected, demonstrating a fundamental difference with respect to visual attention. A qualitatively identical pattern of results was encountered by Schiller and Lee (1991), who used similar visual search tasks to assess the effect of a lesion in extrastriate area $\mathbf{V} 4$ of the macaque.

IKey words: visual search, attention, texture, salience, saliency map, $\mathbf{V} 4]$

Visual attention is one of perhaps several mechanisms that modulate the processing of visual information in the primate brain (for reviews, see Heilman et al., 1990; Posner and Petersen, 1990; Colby, 1991; Kinchla, 1992; Posner and Driver, 1992). Although it has been clear since Helmholtz (1850) and James (1890) that visual attention accomplishes a perceptual selection, visual attention remains poorly understood in many respects. For cxample, numerous questions remain about what kinds of criteria visual attention can use to select a stimulus, or even about why sclection by visual attention occurs in the first place.

Several behavioral methods have been devised for the study

\footnotetext{
Received Jan. 4, 1993, revised May 12, 1993; accepted July 6, 1993.

I am indebted to John Rubin. Jack Gallant, Pietro Perona, and Christof Koch for critical readings of an earlier version of the manuscript and to David Van Essen and Bela Jules\% for hetpful discussions. This work was supported by ONR Grant N00014-89-JII92

Correspondence should be addressed to Jochen Braun, California Institute of Technology, Division of Biology 216-76, Pasadena, CA 91 125.

Copyright 01994 Society for Neuroscience $0270-6474 / 94 / 140554-14505.00 / 0$
}

of visual attention, but the method that arguably has proven most informative is visual search (c.g., Neisser, 1967; Schneider and Shiffrin, 1977; Sperling and Melchner, 1978; Treisman and Gelade, 1980; Nakayama and Silverman, 1986; Treisman, 1988; Duncan and Humphreys, 1989; Cave and Wolfe, 1990). In visual search, several items are presented simultaneously and the observer attempts to detect a particular item (target) among those present. Depending on the types of items involved, the deployment of visual attention follows different strategies: in some cases, visual attention scans the display item by item until the target is found, and in others, visual attention shifts directly to the item being sought, evidently because this item has alteady been located with the help of parallel, preattentive mechanisms (Treisman and Gelade, 1980; Julesz, 1981).

A good example of these two attentional strategies is provided by visual search among items of different salience (Treisman, 1985; Treisman and Souther, 1985; Treisman and Gormican, 1988). When the target of a search is less salient than the distractors ("visual search for minimum of salience." Sfmin), search times increase steeply with the number of distractors, implying sequential scanning by visual attention. However, when the target is more salient than the distractors ("visual search for maximum of salience," $S(\max )$, search times are relatively independent of the number of distractors, implying that the search task is solved primarily by preattentive mechanisms. Interestingly, which attentional strategy is used appears to be independent of which stimulus feature causes the difference in salience (e.g., item size, contrast, or curvature).

Visual search has also been used in the context of attempts to localize visual function by lesioning various parts of the visual system of macaque monkeys (Schiller et al., 1986, 1990a,b; Schiller and Lee, 1991). In the course of such studies. Schiller and Lee (1991) observed that S/max and S/min are differentially affected by a lesion in extrastriate area V4: ablation of this area impaired $S \mathrm{fmin}$ severely, but left $S \mathrm{fmax}$ relatively unaffected. This was observed no matter which stimulus dimension controlled the salience of search items: differences in the size, contrast, color saturation, pattern, velocity of motion, or binocular disparity of the items of the search all produced the same outcome.

Since visual attention is known to modulate ncural activity in arca V4 (Moran and Desimone, 1985; Haenny et al., 1988; Spitzer et al., 1988; Desimone et al., 1990a), visual attention is probably among the processes that are disrupted by a lesion in area V4. If the lesion would spare parallel, preattentive mechanisms, then its differential effect could be explained by the fact that $S / m i n$ and $S f m a x$ involve different attentional strategies: Sfinin, which requires multiple shifts of visual attention, would 
be affected more severely than $S$ fmax, which relies on parallel, preattentive mechanisms. In other words, the findings of Schiller and Lee (1991) would be consistent with an anatomical segregation of attentive and preattentive visual mechanisms.

However, the differential effect of the lesion can also be explained in another way. Sfmax is generally an easier visual task-that is, it is performed with shorter reaction times and/ or lower error rates-than Sfmin (Julesz, 1981; Beck, 1982; Treisman, 1985; Guernsey and Browse, 1987). Accordingly, if the effect of the lesion were proportional to the perceptual difficulty of the search, as would be the case if the search mechanism "degraded gracefully" when damaged, the observations of Schiller and Lee (1991) could also be explained.

To decide between these alternative explanations of the findings of Schiller and Lee (1991), the present study aimed to determine whether $S f \max$ and $S$ fmin differ primarily with respect to perceptual difficulty, or whether the difference is more fundamental and relates to visual attention. Visual search tasks similar to those employed by Schiller and Lee (1991)-that is, search among items of different size, contrast, color saturation, and pattern-were investigated in two steps. The first step consisted of devising instances of Sfmin and Sfmax that exhibited comparable perceptual difficulty - as assessed by measurements of observer performance, signal-to-noise level, and stability of decision criterion. The second step consisted of removing visual attention from the target and distractors of the visual search, something that was achieved by requiring observers to carry out another visual task concurrently (Kahneman, 1973; Braun and Sagi, 1990).

The method of posing a concurrent visual task in order to remove visual attention from other parts of the display, and of asking observers to attempt to report attributes of both the attended and unattended parts, has been used in other contexts. With the help of this method, it has been shown, for example, that visual texture is processed even in the absence of visual attention (Braun and Sagi, 1990, 1991; J. Braun and B. Julesz, unpublished observations), whereas Gestalt grouping (Wertheimer, 1923; Koffka, 1935) requires allocation of visual attention (Ben-Av et al., 1992; Braun and Bauer, 1993).

Removing visual attention from Sfmin and Sfmax of comparable perceptual difficulty should produce one of two outcomes: if the two types of search differ fundamentally, removing visual attention will mimic the effect of a lesion in area V4 and impair Sfmin more severely than Sfmax. If they do not, removing visual attention will affect $S$ fmin and Sfmax comparably. Each outcome would favor one particular explanation of the findings of Schiller and Lee (1991).

\section{Materials and Methods}

Visual tasks

Search tasks. Six pairs of visual search tasks were investigated, with each task pair involving the same two display elements. Figure 1 depicts all search tasks schematically, and Figures 2 and 3 reproduce the actual stimuli of some of the experiments involving search tasks. All search tasks were modeled on the tasks used by Schiller and Lee (1991).

Target and distractor items of search tasks appeared in the periphery of the display, namely, at six locations forming a regular hexagon at $4.3^{\circ}$ of eccentricity. The six locations were chosen from 24 possible locations in such a way that each of the four possible hexagons was equally probable. The six items consisted either of one target and five distractors, or of six distractors (and no target). Within the hexagon, target position was randomized. Observers were instructed to inspect the six items and to report the presence or absence of a target.

Target and distractor elements differed with respect to either size,
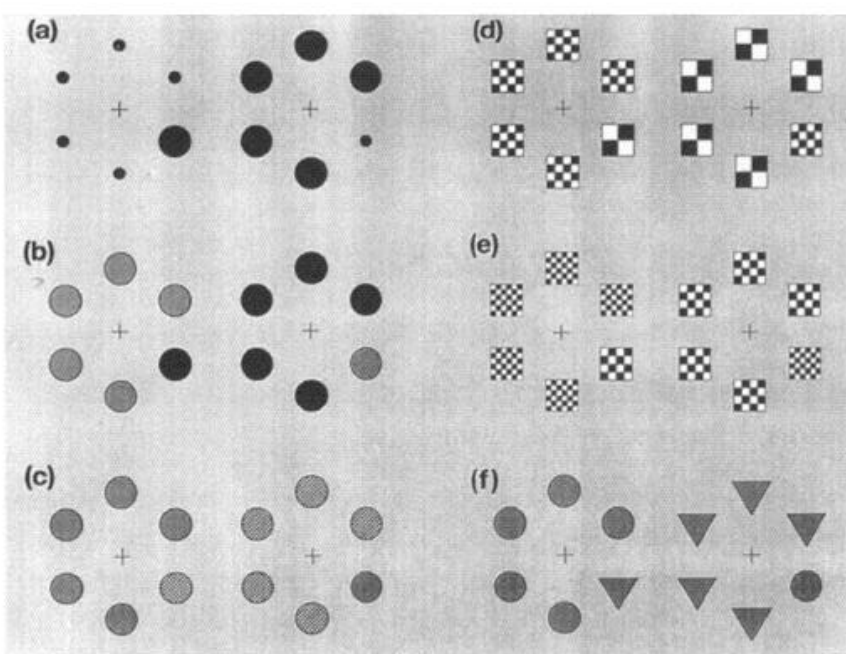

Figure 1. Schematic summary of visual search tasks, drawn with negative contrast. Each search task is represented by one target and five distractor items, forming a regular hexagon around a fixation mark. Tasks involving identical elements are paired. $a-e$. The left task in each pair constitutes Sfmax, and the right task, Sfmin. a, Tasks based on larger and smaller elements (Size-Max, Size-Min). Actual elements were bright red on a dark background. $b$. Tasks based on lighter and darker elements (Contrast-Max, Contrast-Min). Actual elements were white and gray on a dark background. $c$. Tasks based on elements of saturated and unsaturated hue (Color saturation-Max, Color saturation-Min). Actual elements were red (cross-hatching) and isoluminant white (solid) on a dark background. $d$ and $e$, Tasks based on elements of coarse, intermediate, and fine pattern (Pattern-I-Max, Pattern-I-Min, PatternII-Max, Pattern-II-Min). $f$. Tasks based on triangular and circular elements (Triangle-in-Circles, Circle-in-Triangles). Actual elements were bright green on a dark background.

contrast, color saturation, pattern, or shape. As a result, target and distractor elements usually exhibited different salience (see Results). For example, a larger display element was more salient than a smaller element, a higher-contrast (lighter) display element more salient than a lower-contrast (darker) element, and a display element of saturated hue (bright red) was more salient than a display element of neutral hue (equiluminous gray). Display elements of different patterns ("checkerboards") also differed in salience; more coarsely checkered elements being more salient than the more finely checkered ones. Three different patterns were used: coarse $(2 \times 2)$, intermediate $(4 \times 4)$, and fine $(6 \times$ 6 ) checkering. The exact parameters of all display elements are listed in Table 1 .

Each visual search task was named to indicate (1) the way in which target and distractor items differed and (2) whether it constituted Sfmax or Sfmin.

Five search tasks constituted Sfmax (visual search for a maximum of salience): search for a larger target among smaller distractors (named Size-Max), lighter target among darker distractors (Contrast-Max), target of saturated hue among distractors of neutral hue (Color saturationMax), coarsely checkered target among intermediate distractors (Pattern-I-Max), and intermediate target among finely checkered distractors (Pattern-II-Max) (see Fig. 1).

Five further search tasks constituted $S$ fmin (visual search for a minimum of salience): search for a smaller target among larger distractors (Size-Min), darker target among lighter distractors (Contrast-Min), target of neutral hue among distractors of saturated hue (Color saturation$\mathrm{Min}$ ), intermediate target among coarsely checkered distractors (Pattern-I-Min), and finely checkered target among intermediate distractors (Pattern-II-Min) (see Fig. 1).

For visual search based on shape, two further search tasks involved display elements of different shape but equal luminosity and contrast. Since these elements exhibited comparable salience, the search tasks in question could not be classified as Sfmax or Sfmin. Search for a triangular target among circular distractors was named Triangle-in-Circles, and search for a circular target among triangular distractors was named Circle-in-Triangles (see Fig. 1). 
Table 1. Parameters of display elements

\begin{tabular}{llclll} 
Description & Observers & $\begin{array}{l}\text { Lumi- } \\
\text { nance } \\
\left.\text { (cd/m } / \mathrm{m}^{2}\right)\end{array}$ & Huc & $\begin{array}{l}\text { Ra- } \\
\text { dius } \\
\text { (min) }\end{array}$ & Shape \\
\hline Letter-shaped & all & 158 & white & - & L or T \\
Larger & JB, HM & 52 & red & $20^{\prime}$ & round \\
& AG, LS & 90 & red & $17^{\prime}$ & round \\
Smaller & JB, HM & 52 & red & $10^{\prime}$ & round \\
& AG, LS & 90 & red & $9^{\prime}$ & round \\
Lighter & RK, AG & 138 & whitc & $17^{\prime}$ & round \\
& JB & 96 & red & $17^{\prime}$ & round \\
Darker & RK, AG & 42 & white & $17^{\prime}$ & round \\
& JB & 12 & red & $17^{\prime}$ & round \\
Saturated & RK, AG & 90 & red & $17^{\prime}$ & round \\
& JB & 48 & red & $17^{\prime}$ & round \\
Unsaturated & RK, AG & 88 & white & $17^{\prime}$ & round \\
& JB & 48 & white & $17^{\prime}$ & round \\
Coarse & all & $5 / 158$ & white & $26^{\prime}$ & $2 \times 2$ squares \\
Intermediate & all & $5 / 158$ & white & $26^{\prime}$ & $4 \times 4$ squares \\
Fine & all & $5 / 158$ & white & $26^{\prime}$ & $6 \times 6$ squares \\
Triangular & all & 52 & green & $26^{\prime}$ & triangle \\
Circular & all & 52 & green & $17^{\prime}$ & circle
\end{tabular}

For stimuli involving larger and smalter, lighter and darker, and saturated and unsaturated (observer JB) elements, the background luminance was $5 \mathrm{~cd} / \mathrm{m}^{2}$. For stimuli involving elements of saturated and unsalurated hue (observers RK, AB). of coarse. finc. and intermediate pattern, and of triangular and circular shape, background luminance was $30 \mathrm{~cd} / \mathrm{m}^{\prime}$. Letter-shaped display elements consisted of lines measuring $26 \mathrm{~min}$ in length and $5 \mathrm{~min}$ in width.

Nole that atl nomcircular display elements (i.e., triangular and checkered elements) were shown in random states of rotation. Specifically, each such element was independently rotated around its center of gravity by one of eight possible angles: $22.5^{\circ}, 67.5^{\circ}, \ldots$ or $337.5^{\circ}$.

All masking patterns for scarch tasks were constructed in the way shown in Figure 2: at 24 peripheral locations there appeared randomly one of the two display elements relevant to the search task - that is. larger and smaller display elements in the case of Size-Max or SizeMin, lighter and darker display elements in the case of Contrast-Max and Contrast-Min, and so on. When the masking pattern called for noncircular elements, these were rotated individually and independently.

Detection and discrimination tasks. To assess the detectability of individual display elements in the absence of distractors, the search stimuli were ruvdified by omitting all distractor elements. The masking pattern was left unchanged, however. As a result, the stimulus contained (at the 24 peripheral locations) either a single display element, or none at all, and therefore posed a detection task in which observers were instructed to report the presence or absence of that element. The stimuli of two experiments involving detection tasks are shown in Figure 3.

Five detection tasks concerned more salient display elements: the detection of a larger clement (named Size-Hi), a lighter element (ConIrast-Hi), an element of saturated hue (Color saturation-Hi), a coarsely checkered element (Pattern-I-Hi), and an element of intermediate checkering (Pattern-II-Hi). Four detection tasks concemed less salient display elements: the detection of a smaller element (named Size-Lo), a darker element (Contrast-Lo), an element of neutral hue (Color saturation- $L o)$, and of a finely checkered element ( Pattem- $I-L o)$. (The seemingly missing detection task, Pattern-l-Lo, would have been the same as Pattern-II-Hi.)

A final task investigated the discriminability of triangular and circular display elements in the absence of distractors. Exactly one display elcment appeared (at one of the 24 peripheral locations), and its shape was triangular or circular with equal probability. The maskung pattern was the same as for the search tasks involving triangular and circular elements. In this discrimination task, which was named Triangle/Circle. observers were instructed to report the shape of the single display element.

Letter task. The letter task concerned T- or L-shaped elements near the center of the display. These elements could appear at seven possible locations: the exact center of the display and six locations at $1.0^{\circ} \mathrm{ec}-$ centricity, spaced evenly around the center. On any given trial. five Tor L-shaped elements were distributed randomly over the seven possible locations, as well as rotated randomly and independently, resulting in a large number of possible configurations. There appeared either five Ts, five Ls, four Ts and one L, or four Ls and onc T. Observers were instructed to report whether all elements were the same (five $\mathrm{Ts}_{\mathrm{s}}$ five I.s) or whether one was different from the other four (four Ts and one L. four Ls and one T). Stimuli of experiments involving the letter task are shown in Figure $2 b$ and in Figure $3 a-d$.

Masking patterns for the letter task were constructed with $\Gamma$-shaped display elements. Five such elements appeared at the same locations as the five T-or L-shaped elements of the stimulus pattern, but in different states of rotation. An example of a masking pattern for the letter task is shown in Figure $2 h$.

\section{Psychophysical manipulations}

Obraining comparable performance. To obtain observer performance near the level of $8.4 \%$ correct, or $d^{\prime}=2$, (criterion performanco), a suitable SOA (stimulus onset asynchrony, the time between stimulus and mask onset) was chosen for every task and observer. It was assumed that SOA is one of the variables determining effective stimulus contrast. The SOA at which an observer achieves criterion performance was termed criterion SOA. Among the various tasks investigated here, criterion SOA ranged from approximately $30 \mathrm{msec}$ to approximately $180 \mathrm{msec}$. Among search tasks, criterion SOA ranged from approximately $75 \mathrm{msec}$ to approximately $150 \mathrm{msec}$ (Fig, 4).

Two control experiments investigated whether masuring performance at different SOAs was sufficient to produce search tasks that were comparable not only with respect to performance but also with respect to other psychophysical measures of perceptual difficulty.

Noise at peripheral locations. To change the effective stimulus contrast in search tasks, identical sets of small $\left(0.06^{\circ} \times 0.06^{\circ}\right)$, bright $(158 \mathrm{~cd} /$ $\mathrm{m}^{2}$ ) dots were placed over the six target and distractor items of the search. Eight dots (for some observers, 12 dots) were placed randomly in a region of $0.6^{\circ} \times 0.6^{\circ}$ over each item. A different dot configuration was generated for every trial. The superposition of these dots was expected to reduce the discriminability of target and distractor items and. thus, to reduce effective stimulus contrast. Two examples for the stimuli used in these experiments are shown in Figure 3, $f$ and $h$.

Intermixing of stimulus types. To affect the stability of the decision criterion in search tasks, different types of search were randomly intermixed, so that observers could no longer predict the type of target and distractor item that would constitute the next trial. This manipulation was expected to increase variability in the decision criterion and therefore to lower performance. Scarch tasks intermixed were in two groups of four: Size-Max, Size-Mirt, Triangle-in-Cirlt, and Circlc-in-Triangle (Girst group), and Lighiness-Max, Lighmess-Min, Pattorm-I-Max, and Pattern-I-Min (second group). Observers were instructed to report the presence or absence of a unique display element (rather than the presence or absence of a particular type of target element), and performance was analyzed separately for each slimulus type.

Concurrent execution of letter task. To determine how visual search is affected by concustent execution of the letter task, a composite stimulus was constructed comprising the display clements relevant for both tasks. Examples of such stimuli are shown in Figure $2 b$ and in Figure $3 a-d$. Central and peripheral display elements (rclevant for letter and scarch task. respectively) were entirely independent in all respects in which they varied randomly - for example, the configuration ("same" or "different") of the T- and L-shaped central elements was independent of the presence or absence of a target item among the peripheral elcments. Data were collected separately for three types of instructions:

The first instruction required observers to carry out the letter task as well as possible while ignoring the display elements Jele vant to the search task. Observers responded as appropriate for the letter task; that is, they reported whether the central elements were the "same" or "different." This result was a baseline performance for the letter task, termed separate performance of the letter lask.

The second instruction was the opposite of the first and required observers to carry out the search task as well as possible while ignoring the display elements relevant to the letter task. Observers responded as appropriate for the search task: that is. they reported whether a target was "present" or "absent." A baseline performance for search task. namely, separate performance of the search task, was the result. 


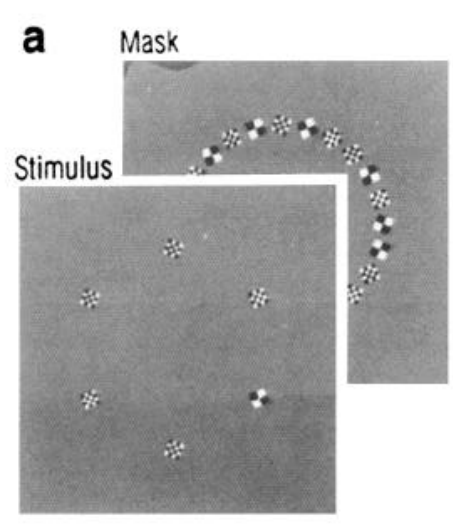

Task: 8 present or absent?

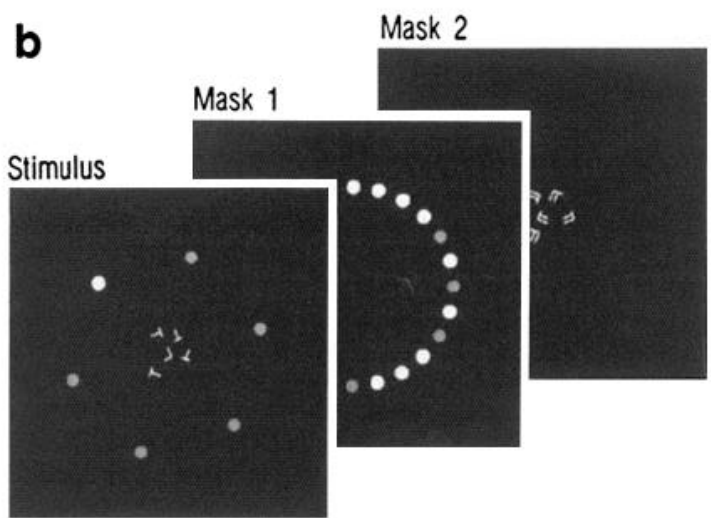

Task A: letters same or different? Task B: - present or absent?
Figure 2. Trial sequences and tasks. $a$. In Experiment 1, the stimulus ( front) was followed by a single mask (back). In the example shown, the observer searched for a coarsely patterned target among distractors of intermediate pattern. $b$. In Experiment 2, the stimulus (front) was followed by a mask for peripheral elements (middle) and, separately, a mask for central elements (back). With respect to central elements, the observer carried out the letter lask (Task A). With respect to peripheral elements, the observer searched for a lighter element among darker distractors (Task B).
The third instruction constituted the experiment proper. It required observers to attempt both tasks as well as possible, although with unequal priority. The letter task was designated primary, and observers were encouraged to reach baseline performance on that task. The search task was designated secondary, and observers were asked to perform only as well as possible without compromising the letter task. After each trial, observers reported on the letter task first ("same" or "different") and on the search task second ("present" or "absent"). In this way, two performance levels were measured simultaneously, which were termed concurrent performance of the letter task and concurrent performance of the search task, respectively.

In evaluating the results, two comparisons were of interest. The comparison of separate and concurrent performance of the letter task revealed whether the observers had attended fully to the letter task. The comparison of separate and concurrent performance levels of the search task revealed the extent to which search performance depended on visual attention.

Analogous experiments were conducted with detection and discrimination tasks in the place of visual search tasks.

\section{Psychophysical analysis}

Performance measure. All results are reported in terms of unbiased performance. Unbiased performance is defined as the discriminability, $d^{\prime}$, expressed as percentage correct. The rationale for choosing this somewhat unconventional performance measure is given below.

Signal detection theory (Green and Swets, 1966) relates performance to a hypothetical signal-to-noise ratio by assuming that a stimulus gives rise to a scalar signal with normally distributed noise, that is, a signal characterized by a mean, $\mu$, and a variance, $\sigma^{2}$. If there are two alternative
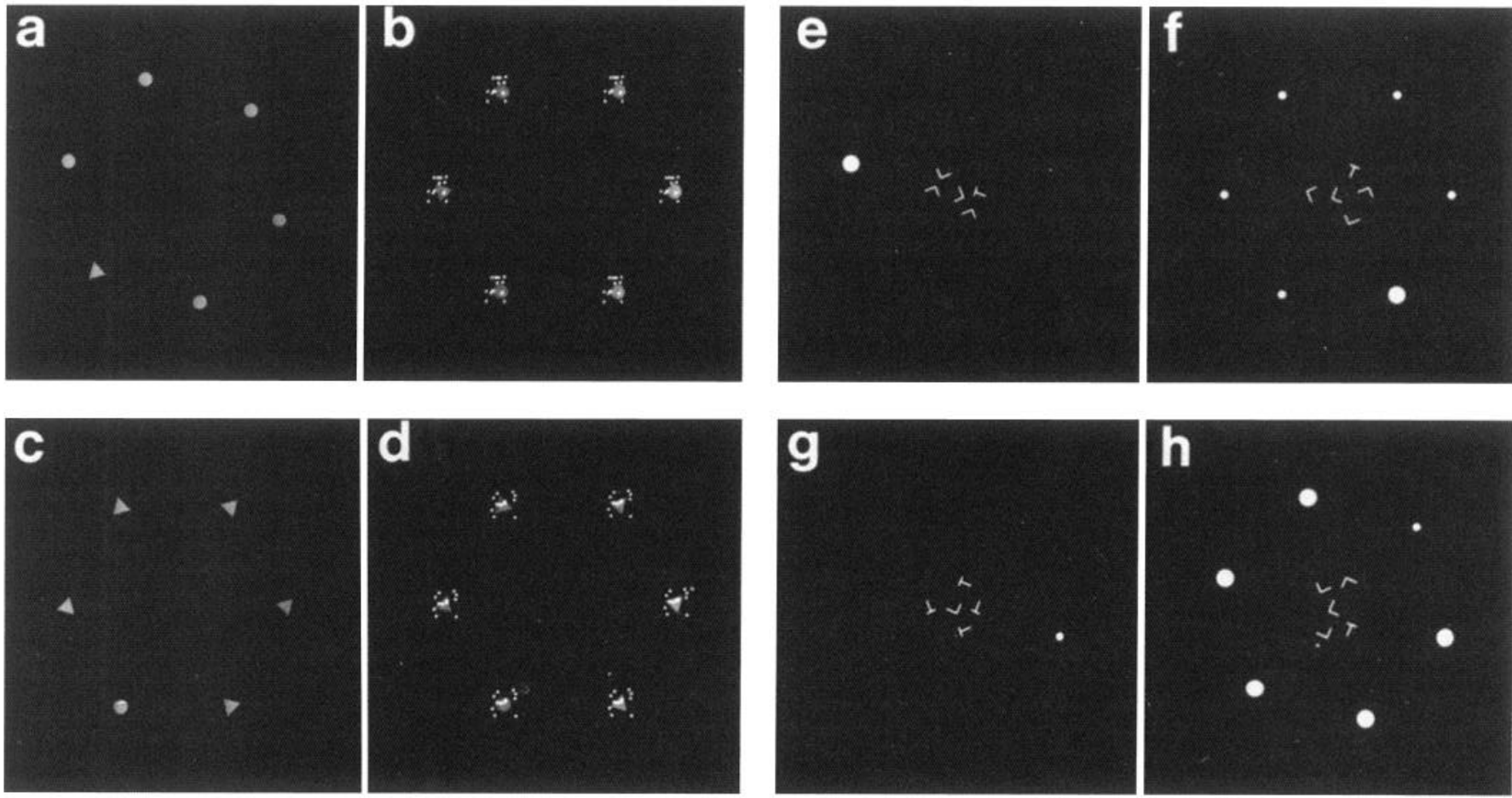

Figure 3. Example stimuli for Experiments 1 and 2. $a$. Search for a triangular element among circular elements (Triangle-in-Circles). $b$, Trianglein-Circles with noise at peripheral locations. $c$, Search for a circular element among triangular elements (Circle-in-Triangles). $d$. Circle-in-Triangles with noise at peripheral locations. $e$, Letter task combined with detection of a large display element (Size-Hi). f. Letter task combined with search for a large target among small distractors (Size-Max). $g$, Letter task combined with detection of a small element (Size-Lo). $h$, Letter task combined with search for a small target among large distractors (Size-Min). 
(a)

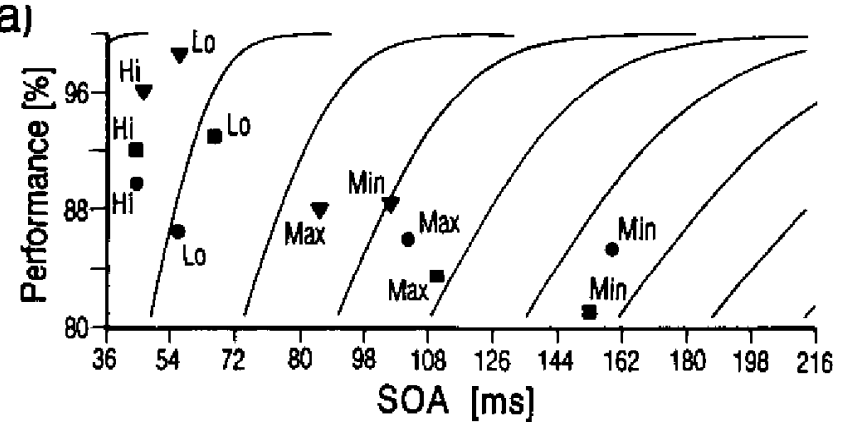

(b)

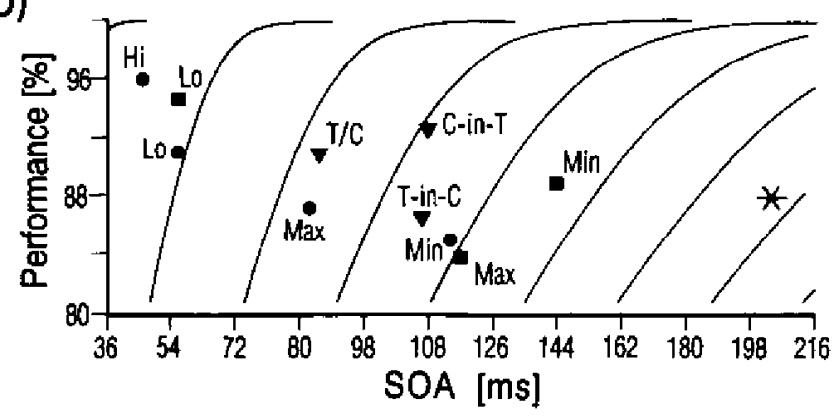

Figure 4. Average SOA and performance for all tasks investigated. Different tasks were carried out at different SOAs in order to obtain performance near $84 \%$ correct. Tasks based on the same type of display elements are represented by the same type of symbol $(\boldsymbol{\omega}$, or $\mathbf{\Delta})$. Symbols representing $S / \max$ and $S f \mathrm{~min}$ are labeled $\mathrm{Max}$ and $\mathrm{Min}$, respectively. Symbols representing the detection of a more or less salient element are labeled $H i$ and $L O$, respectively. Symbols representing tasks with triangular and circular clements are labeled as follows: Trianglein-Circles $(T-i n-C)$, Circle-in-Triangles ( $C$-in-T), and Triangle/Circle $(T / C)$. The curved lines are representative psychometric curves (see Materials and Methods). The figure is divided into two parts to improve readability. $a$, Tasks involving larger or smaller elements ( $(\boldsymbol{)})$, lighter or darker elements $(\mathbf{D})$, and elements of saturated or unsaturated hue ( $\boldsymbol{(})$. $b$. Tasks involving elements of coarse or intermediate pattern (C), elements of intermediate or fine pattern (D), and elements of triangular or circular shape ( $\Delta)$. The letter task is represented by the asterisk $\left({ }^{*}\right)$. For a given type of display element, the psychometric curve of Sfmax is consistently to the left of Sfmin. Similarly, the psychometric curve for the detection of a more salient element is generally to the left of the less salient element.

stimuli, $A$ and $B$, the observer is assumed to decide between two signals, $\mu$, and $\mu_{i}$, by adopting a decision criterion $\theta \in\left[\mu_{1}, \mu_{A}\right]$. Given these assumptions. the relative signal levels of $\mu_{f}, \theta$, and $\mu_{n}$ can be inferred from the fraction of correct responses to each of the two stimulus types,

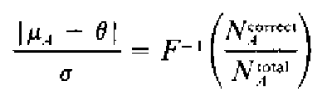

and

$$
\frac{\left|\mu_{\theta}-\theta\right|}{\sigma}=F^{-1}\left(\frac{N_{B}^{\text {correct }}}{N_{\theta}^{\text {Litgi }}}\right)
$$

where $N_{s, s}$ and $N_{t, s}$ are the number of correct and total responses, respectively, and $F^{-1}$ ( ) is the inverse function of the normal distribution,

$$
F(s)=\int_{-\infty}^{t} \frac{1}{\sqrt{2 \pi}} e^{-1 / 2 x^{2}} d x
$$

Discriminability, $d^{r}$, is defined as the distance between the mean signal levels, $\mu_{1}$ and $\mu_{b}$, in units of $\sigma$, and can be computed as

$$
d^{r}=\frac{\left|\mu_{1}-\mu_{s}\right|}{\sigma}=\frac{\left|\mu_{2}-\theta\right|}{\sigma}-\frac{\left|\mu_{\mu}-\theta\right|}{\sigma}
$$

The advantage of $d^{\prime \prime}$ is that it is independent of the decision criterion, $\theta_{*}$ which in practice is often biased toward either $\mu_{A}$ or $\mu_{H}$.

Alternatively, one may compute unbiased performance as the fraction of correct responses that would have been obtained if the decision criterion had been placed where it would have resulted in the smallest number of errors, namely, exactly between $\mu_{4}$ and $\mu_{s}$ :

$$
\frac{N^{\text {carmect }}}{N^{\text {Nis:al }}}=f\left(\frac{d^{\prime}}{2}\right)
$$

In addition to being independent of the decision criterion, unbiased performance has the advantage of being expressed in more intuitive units, namely, percentage correct. In the present report, all results are given in terms of unbiased performance.

Psychometric functions. The monotonic increase of visual performance with SOA is called the psychometric function. Partial psychometric functions (at least two SOA values) were established for al] tasks, and more complete psychometric functions (at least four SOA values) were established for selected search tasks as well as for the letter task. Empirical psychometric functions often exhibit an inflection point (maximal first derivative) near $75 \%$ correct performance. To give a rough quantification of the observed psychometric functions, visual search for salience maxima (Size-, Lightness-, Color saturation-Max) reached $75 \%$ correct pefformance at an average SOA of $94 \pm 7$ msec, exhibiting an average slope of $0.7 \pm 0.2 \% \mathrm{msec}$ '. In the case of visual search for salience minima (Size-, Lighiness-, Color saturation-Min), the corresponding values were $111 \pm 16 \mathrm{msec}$ and $1.1 \pm 0.3 \% \mathrm{msec} !$, respectively, and for the letter task the same values were $162 \pm 10 \mathrm{msec}$ and $0.4 \pm 0.1 \% \mathrm{msec}$.

As is often the case (Green and Luce, 1975; Nachmias, 1981), the observed psychometric functions were of roughly identical shape when plotted as a function of $\log (S O A)$. To capture this property it is necessary to assume a slightly different functional shape (which does not exhibit an inflection point at $75 \%$ correct performance), for example, the Weibull function (Weibull, 1951),

$$
\frac{N^{\text {correc }}}{N^{\text {(mata) }}}=1-\frac{1}{2} \exp \left[-\left(\frac{S O A}{S O 4_{1}}\right)^{\prime \prime}\right] .
$$

The representative psychometric functions in Figure 4 were computed from this function, with $S O A_{11}=24 \mathrm{msec}, 48$ msec, . . and $\beta=3.5$. The value of $\beta$ is typical for tasks with iwo alternative stimuli.

\section{Miscellaneous}

Observers. Ten experienced observers participated in the experiment. Nine were undergraduate students at Caltech (AG, BR, HM, LS, MA. RS, SW, SC, TI) and one was the author (JB). Not all observers participated in all experiments, but every condition was investigated with at least two observers. Observers worked for is sessions over a period of 3 weeks; some were recalled for a second set of 15 sessions. All observers had normal (or corrected to normal) vision

Apparatus. Stimuli were generated by a raster display system (Adage 3106) with a Microvax II (Digital) as host computer and displayed on a high-resolution color monitor' (Hitachi). Monitor resolution was 512 $\times 512$ pixels. Lightness and color of each pixel were determined by 3 $\times 8$-bit RGB values. The frame rate was $55.5 \mathrm{~Hz}$, permitting display times to be varied in steps of $18 \mathrm{msec}$. Viewing was binocular, from a distance of approximately $110 \mathrm{~cm}$, resulting in a display of approximately $14.5^{\circ} \times 14.5^{\circ}$ of visual angle. No chin rest was used. Before each trial sequence, observers fixated a mark at display center. Because of the short duration of the trial sequence, there was no need to otherwise control eye position. Mean luminance was $5 \mathrm{~cd} / \mathrm{m}^{2}$ for some experiments, and $30 \mathrm{~cd} / \mathrm{m}^{2}$ for others (Table 1). Ambient illumination was approximately $5 \mathrm{~cd} / \mathrm{m}^{2}$.

Trial sequence. To prevent planned saccades, the trial sequence began with an empty interval (mean luminance) of random duration (180$360 \mathrm{msec}$ ). Next, the stimulus was presented ( $36 \mathrm{msec}$ ), followed by an empty interval of fixed duration, and by the presentation of the first mask ( $72 \mathrm{msec}$ ). In experiments involving the letter task, there followed another empty interval of fixed duration and the presentation of the second mask $(72 \mathrm{msec})$. The relatively short duration of the trial sequence precluded a second fixation. Visible persistence (Coltheart, 1980) can be assumed to last from approximately the onset of the stimulus interval to approximately the onset of the relevant mask interval. This length of time is usually termed stimulus onset astnchrony or SOA. 
After viewing the trial sequence, observers responded by striking one of two keys on a computer keyboard. A mistaken response elicited immediate auditory fecdback.

Order of data collection. Although observers were practised, performance generally continued to improve somewhat during data collection. To ensure that all critical comparisons were based on comparable states of practice. concurrent and separate performance, performance with and without noise, and performance with and without intermixing of stimuli were in vestigated during the same sessions for any given task. Data were collected in blocks of 100 trials, except in the experiment using intermixed stimulus types, in which case blocks of 400 trials were used.

\section{Results}

Porformance as a function of $\mathrm{SO} A$

To obtain comparable levels of performance for different visual tasks, the SOA was adjusted for each task and observer as needed to obtain a performance of approximately $84 \%$ correct (critcrion prommance: sec Materials and Methods). The range of SOAs that had to be used in order to obtain comparable performance is shown in Figure 4. As differences between observers were generally small compared to differences between lasks, the symbols in Figure 4 represent the observer average of the SOA at which each task was investigated, as well as the observer average of the resulting performance level of each task (roughly $84 \%$ correct). Representative psychometric functions (curved lines in Figure 4) were used to estimate the intersect with the $84 \%$ correct level, which was termed criterion SO.1 (SOA at $84 \%$ correct; see Materials and Methods). Criterion SOA was used as an entirely empirical measure of the "perceptual difficulty" of the task in question, a measure that intentionally confounds all factors that might limit performance.

Detection tasks - which measured the detectability of a single target item in the absence of distractor items-cxhibited the lowest criterion SOAs of all tasks investigated (30-50 msec range; Fig. 4). For search tasks - which measured target detectability in the presence of distractor items-criterion SOAs were considerably higher (75-150 msec range). Even search tasks involving less salient distractors exhibited consistently higher criterion SOAs than detection tasks, demonstrating that even less salient distractors were sufficiently salient to change the nature of the task from a detection to a search. The longest criterion SOA of any task investigated here was that of the letter task (approximately $180 \mathrm{msec}$ ).

In general, the relative salience of display elements predicted the relative criterion SOAs of both detection and search tasks (Fig. 4). For example, the detection of a larger, lighter, or more coarsely checkered display clement (Size-, Contrast-, PatternI- $/ \mathrm{h}$ ) exhibited shorter criterion SOAs than the detection of a smaller, darker, or more finely checkered display element, respectively (Size-, Contrast-, Pattern-I-Lo). Between corresponding instances of $S$ fmax and Sfmin, the criterion SOA differed by approximately $55 \mathrm{msec}$ (search among larger and smaller display clements: Size-Mar and Si-e-l. fim), $40 \mathrm{mscc}$ (search among lighter and darker elements: (ontrast-Max and - Min). $20 \mathrm{msec}$ (search among elements of saturated and unsaturated hue: (olor saturation-Max and $-\mathrm{Min}$ ), $45 \mathrm{msec}$ (search among elements of coarse and intermediate checkering: Pattern-I-MaX and $-1 \mathrm{fm}$ ), and $10 \mathrm{msec}$ (scarch among elements of intermediate and fine checkering: Pattern- $/$-Max and -Min). In all such pairs of search tasks, the Sfmax exhibited a shorter criterion SOA than the Sfmin. The only cases where relative target salience did not predict relative criterion SOA were the detection of a display element of saturated or neutral hue (Color saruration-
$M i$ and $-L o)$ and the detection of a display clement of intermediate or fine checkering Pattern-H-Hi and - Lo), all of which cxhibited comparable criterion SOAs.

With respect to triangular and circular display elements, the detection tasks showed comparable criterion SOAs (results not shown). Apparently, the difference in shape did not entail a difference in salience. The discrimination of a single triangular or circular display element (Triangle/(irc/e) exhibited a criterion SOA near $80 \mathrm{msec}$ and the search tasks based on these clements (Circle-in-Triangles, Triangle-in-Circles) exhibited criterion SOAs of $105-110 \mathrm{msec}$. The difference between criterion SOAs was sometimes positive and sometimes negative. but always small: two observers showed slightly lower criterion SOAs for Triangle-in-Circles, and two others exhibited lower criterion SOAs for Circle-in-Triangles.

The average performance level of Sfmax and $S / m i n$ was 84.1 $\pm 3.4 \%$ and $84.8 \pm 2.9 \%$ correct, respectively (Table 2 ). This almost exact match was achieved by using an average SOA of $98 \pm 13 \mathrm{msec}$ and $133 \pm 24 \mathrm{msec}$, respectively.

\section{Experiment 1: notse at peripheral locations, intermixing of stimulas types}

Two control experiments measured the effect on Sfmax and $S f$ min of a decrease in (1) effective signal strength and (2) stability of decision criterion. Effective signal strength and stability of decision criterion are the two main variables which, according to signal detection theory (Green and Swets, 1966), characterize the difficulty of a perceptual task. Note that neither of the two manipulations is expected to disturb allocation of visual attention (Sperling and Dosher. 1986).

One way to reduce effective stimulus contrasi would have been to simply decrease SOA. For reasons given in Materials and Methods, it was not possible to establish performance systematically at more than a few different SOAs. Accordingly, reliable psychometric curves were established only for a few of the tasks in question. The available information suggests that dependence of performance on SOA (e.g., the maximal slope of the psychometric curve) is comparable for Sfmax and Sfmin. if one takes into consideration that the former type of visual search tends to exhibit its maximal slope at shorter SOAs than the latter: average slopes were $0.7 \pm 0.2 \% \mathrm{msec}$ ' in the case of Sfmax and $1.1 \pm 0.3 \% \mathrm{msec} '$ in the case of S/min, consistent ( $p>0.1$ ) with the representative psychometric curves shown in Figure 4.

As an alternative way of obtaining information about the effect of reducing effective stimulus contrast. cight instances of visual search (Size', Contrast-, Pattern-I-Max, - Min as well as Triangle-in-Circles and Circle-in-Triangles) were investigated both with and without stimulus noise at peripheral locations (observers SC, SW, BR. MA). Examples of the stimuli used in this experiment are illustrated in Figure $3 c-h$, and the outcome is shown in Figure 5. As expected, the presence of noise at peripheral locations reduced search performance on all tasks. However, the investigated instances of Sfmax and Sfmin were affected to comparable degrees: performance fell by an average of $13.6 \pm 6.6 \%$ correct (Size-, Contrast-, and Pattern-1-Mar), and by an average of $9.5 \pm 3.3 \%$ correct (Size-. Lighness-, and Pallern- $\mathrm{I}-\mathrm{Min}$ ), respectively (Table 2 ). The difference between these values did not reach significance $(p>0,1)$.

In addition to effective stimulus contrast, performance is determined also by the decision criterion adopted by the observer. 

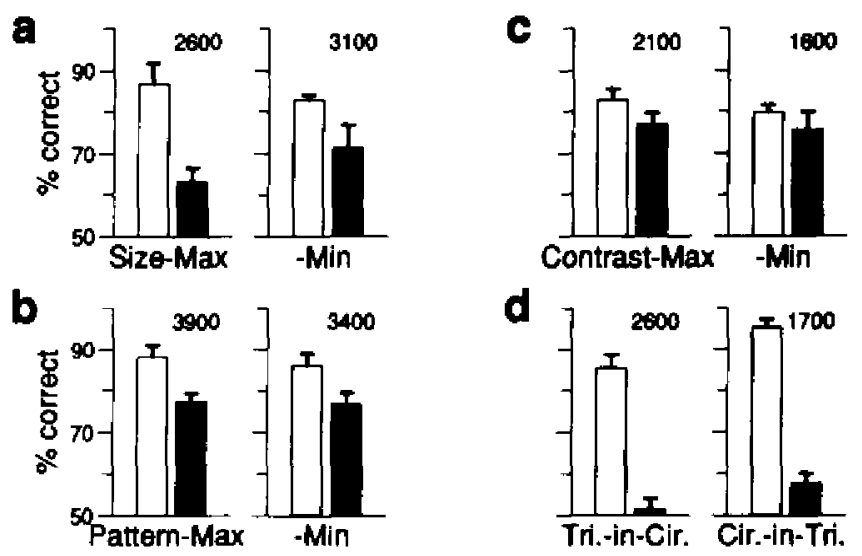

\section{Performance without ( $\square$ ) and with ( $\square$ ) noise}

Figure 5. Effect of noise at peripheral locations (observer averages). $a$, search among larger and smaller elements (Size-Max, Size-Min); $b$, elements of coarse and intermediate pattern (Pattern-I-Max, $M$ Min); $c$, lighter and darker elements (Contrast-Max. - Min) $d$, triangular and circular elements (Triangle-in-Circles, Circle-in-Triangles). Each bar graph shows separate and concurrent performance for a particular task. Error bars represent the average standard error for all observers. The number of trials is given at the top.

When confronted repeatedly with the same type of stimulus ("blocked" stimulus presentation), the observer is able to adopt the decision criterion that minimizes the total number of mistakes. However, when the observer does not know which type of stimulus will appear next ("intermixed" stimulus presentation), the decision criterion will vary and performance will suffer (Sperling and Dosher. 1986).

To determine the effect of an instable decision criterion on Sfmax and S/min, eight instances of visual search were investigated, in two groups of four (Size-Max and -Min. Trianglein-Circles and Circle-in-Triangles, observers SC, SW; Contrast-, Pattern-I-Max and-Min, observers BR, MA). Within each group, the four different stimulus types were randomly intermixed. The outcome of this experiment is shown in Figure 6. Again, Sfmax and Sfmin were affected to comparable degrees: performance fell by an average of $20.2 \pm 6.5$ (Size-, Contrast-, and Pattern$I-\mathrm{Max}$ ) and $12.2 \pm 5.4 \%$ (Size-. (ontrast-, and Pattern-I-Min) respectively (Table 2 ). The difference between these values was not significant $(p>0.1)$.
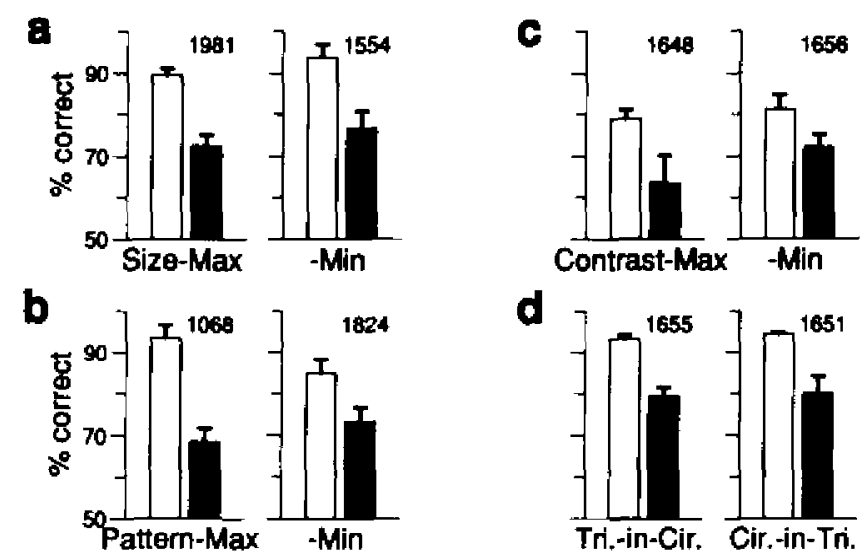

\section{Blocked $(\square)$ and intermixed ( $\square$ ) performance}

Figure 6. Effect of intermixing of stimulus types (observer averages). $a$. search among larger and smaller elements (Size-Max, Sizc-Min); $b$, elements of coarse and intermediate pattern (Pattern-I-Max,-Min); $c$, lighter and darker clements (Contrast-Max, - Min); $d$, triangular and circular elements (Triangle-in-Circles, Circle-in-Triangles). Sce Figure 5 caption for delails.

\section{Experiment 2: concutrent execution of letter task}

Visual attention can be removed from the target item(s) of a visual task by requiring the observer to concurrently carry out the letter task (see Materials and Methods). Twelve types of visual search, ten types of detection tasks, and one type of discrimination task were investigated in this way. The results arc reported in two formats: data for two pairs of search tasks and one observer are presented in full, and data for all other tasks and observers are presented in a more condensed format. The sclection was made on the basis of trial number: the tasks/ observers reported in full were those with the largest number of trials.

Figure 7 shows the outcome of combining the letter task with each of four search tasks: Size-Max, Size-Min (observer HM). Color saturation-Max, Color saturation-Min (observer JB). Scatter plots are used to illustrate the variability of the outcome between different blocks of trials performed by the same observer, each symbol representing performance in 100 trials. As these task combinations were studied at three or more SOAs, separate scatter plots show the results for different SOAs.

\begin{tabular}{|c|c|c|}
\hline & $\begin{array}{l}\text { Visual search for } \\
\text { maximum of salience }\end{array}$ & $\begin{array}{l}\text { Visual scarch for } \\
\text { minimum of salience }\end{array}$ \\
\hline $\begin{array}{l}\text { Concurrent letter } \\
\text { task }\end{array}$ & $\begin{array}{l}84.1 \pm 3.4 \rightarrow 74.4 \pm 3.7 \% \\
(146.00 \text { trials })\end{array}$ & $\begin{array}{l}84.8 \pm 2.9 \rightarrow 58.0 \pm 5.2 \% \\
(12400 \text { trials })\end{array}$ \\
\hline $\begin{array}{l}\text { Noise at peripheral } \\
\text { locations }\end{array}$ & $\begin{array}{l}86.7 \pm 2.0 \rightarrow 73.1 \pm 6.3 \% \\
(8600 \text { trials })\end{array}$ & $\begin{array}{l}83.8 \pm 2.3 \rightarrow 74.3 \pm 2.4 \% \\
(8100 \text { trials })\end{array}$ \\
\hline $\begin{array}{l}\text { Intermixing of } \\
\text { stimulus types }\end{array}$ & $\begin{array}{l}87.7 \pm 5.3 \rightarrow 67.5 \pm 3.8 \% \\
(4697 \text { trials) }\end{array}$ & $\begin{array}{l}86.9 \pm 5.0 \rightarrow 73.7 \pm 2.0 \% \\
(5034 \text { trials })\end{array}$ \\
\hline
\end{tabular}

Data are averages over all stimulus types and observers. Entries describe the effect of a particular manipulation on a particular type of visual search. Each entry gives bascline performance, performance resulting from the manipulation, standard errors for both values. and overall trial number. 

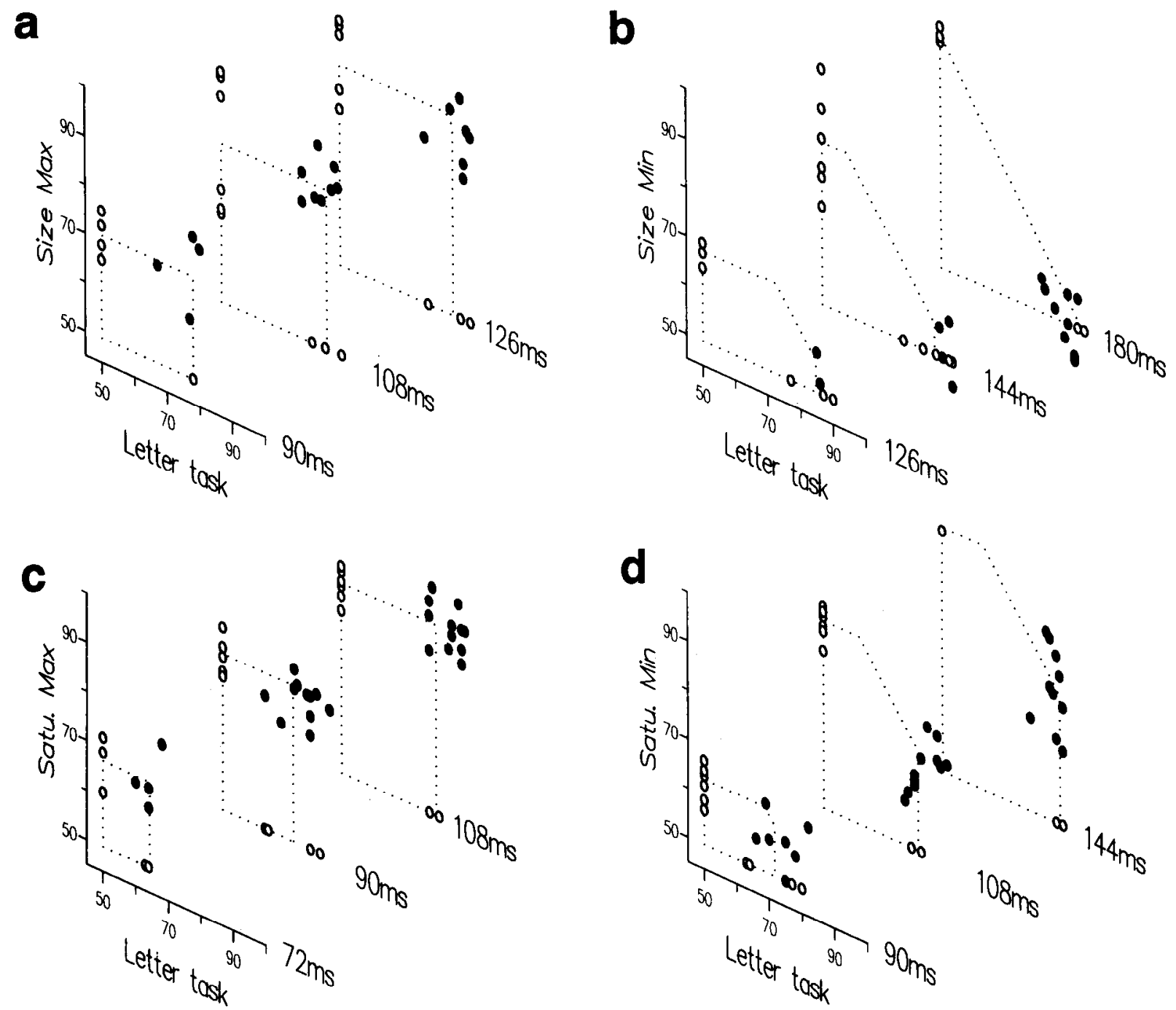

Tasks executed separately $(O)$ and concurrently $(\mathbf{O})$.

Figure 7. Effect of concurrent letter task (individual observers). For each task combination, several scatter plots show data obtained at different SOA values, in orthographic projection. The individual symbols in each scatter plot represent 100 trials. Letter task performance is represented along the "horizontal" axes; search task performance, along the "vertical" axes. Open symbols (O) show separate performance of a particular task and are positioned along the axes of the plot. Solid symbols (๑) show concurrent performance of both tasks and occupy the plane of the scatter plot. Mean performance is indicated by broken lines. a, Letter task and Size-Max. b, Letter task and Size-Min. c, Letter task and Color saturationMax. d, Letter task and Color saturation-Min. When the two tasks conflict, the solid symbols are found in the lower right corner of the scatter plot. When they do not, the solid symbols are located in the upper right corner of the plot.

For the letter task, separate and concurrent performance were comparable in all four task combinations ("horizontal" axes, Fig. $7 a-d$ ), demonstrating that attention was allocated normally to the letter task, even though observers also reported on the search task. In the case of visual search for maxima of salience (Size-Max, Fig. 7a, Color saturation-Max, Fig. 7c, "vertical" axes), separate and concurrent performance were comparable as well. This was true at all SO $\Lambda$ s and showed that removing visual attention left Sfmax largely unaffected. A very different outcome was obtained in the case of visual search for minima of salience. Here, concurrent performance generally fell significantly below separate performance. For Size-Min (Fig. 7b), concurrent performance collapsed to chance level, whereas for Color saturation-Min (Fig. $7 d$ ) performance was reduced to a "floor" somewhat above chance. This outcome, which again held at all SOAs, showed that Sfmin was severely impaired in the absence of visual attention.

The dramatically unequal effect of removing visual attention just described was encountered also with other types of Sfmax and Sfmin and with other observers. These results will now be described in a condensed format (Figs. 8, 9). In the figures, performance is given as the average taken over all obscrvers who performed a particular task combination. The error bars associated with performance were calculated in two steps: for each observer, a standard error was computed from the performance obtained in different blocks of trials, and the error bar was computed as the average of these standard error values.

In Figures 8 and 9, results are grouped by the type of display 

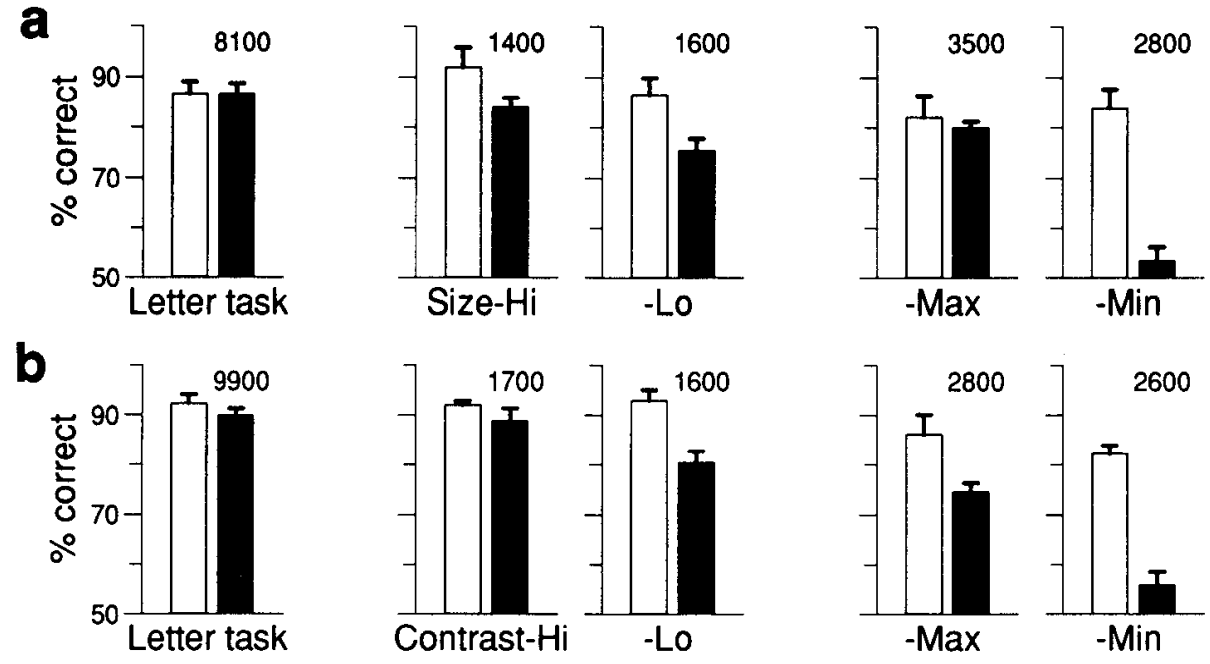

Figure 8. Effect of concurrent letter
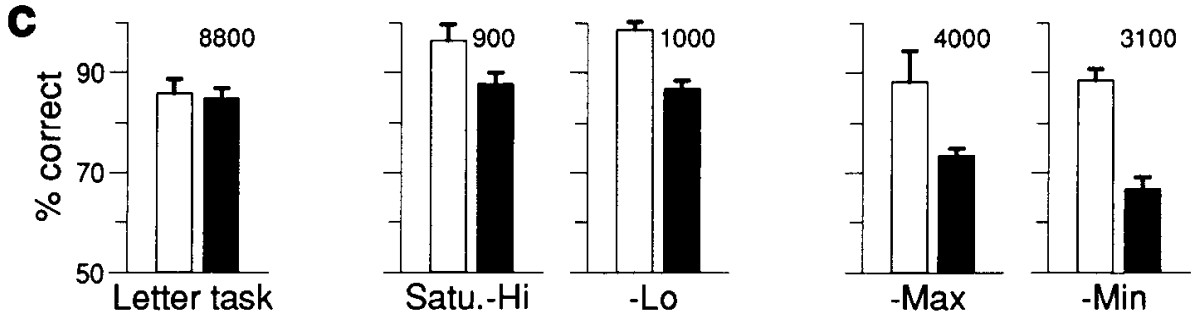

Hi, -Lo,-Max,-Min). Each graph represents separate and concurrent performance for a particular task. Error bars represent the average standard error for all observers. The number of trials is given at the top.

Separate ( $\square$ ) and concurrent ( $\square$ ) performance

element that appeared at peripheral locations. For example, the top row of graphs in Figure 8 shows aggregate results for the four task combinations involving larger and/or smaller display elements: Size-Hi, Size-Lo, Size-Max, and Size-Min (Fig. 8a). Since concurrent and separate performance of the letter task were consistently comparable, it seemed legitimate to pool letter-task performance from all four task combinations. This pooled performance is shown in the leftmost graph of the row. The other four graphs in this row represent performance on the four detection (Size-Lo, - $H i$, observers AG, LS) and search tasks (Size-Max, -Min, observers AG, HM, JB, LS).

Tasks involving other types of display elements are treated similarly: Figure $8 b$ shows results pertaining to tasks involving lighter and/or darker display elements (Contrast-Hi, - Lo, observers AG, RK; Contrast-Max, -Min, observers AG, JB, RK), and Figure $8 c$ shows results pertaining to tasks involving display elements of saturated and/or neutral hue (Color saturation- $H$, -Lo, observers AG, RK; Color saturation-Max, -Min, observers AG, JB, RK).

As mentioned, separate and concurrent performance of the letter task were comparable (Fig. $8 a-c$, leftmost graphs in each row). In the case of detection tasks, concurrent performance was often lower than separate performance (Fig. $8 a-c$, second and third graphs in each row). However, concurrent detection performance remained well above chance level for all display elements, including those of lower salience. In fact, concurrent detection performance was generally comparable for display elements of higher and lower salience. In the case of search tasks, however, the outcome often depended strongly on the relative salience of target and distractor items: Sfmax exhibited relatively high levels of concurrent performance (Fig. $8 a-c$, fourth graph in each row), whereas $S f$ min languished at relatively low levels of performance (Fig. $6 a-c$, rightmost graph in each row). The asymmetry between $S f$ max and $S f m i n$ was particularly large in the case of search based on larger and smaller, or on lighter and darker, display elements. Only a small asymmetry was obtained with search tasks involving display elements of saturated and neutral hue (but see Fig. $5 c, d$ ). Two factors seemed responsible for this less dramatic outcome: observer AG performed poorly on Color saturation-Max (note the large error bar), and all three observers performed Color saturation-Min well above chance level.

Figure 9 summarizes the results concerning tasks involving display elements of different pattern (coarse, intermediate, and fine checkerboards) and shape (triangles and circles). Detection and search tasks involving display elements of coarsc and intermediate pattern (Pattern-I-Hi, -Lo, observers RK, TC; Pattern-I-Max, -Min, observers AG, RK, TC) are reported in Figure $9 a$, and tasks based on display elements of intermediate and fine pattern (Pattern-II-Lo, observers RK, TC; Pattern-II-Max, -Min, observers AG, RK, TC) in Figure $9 b$. Note that Pattern$I I-H i$ is identical to Pattern-I-Lo. Finally, results pertaining to discrimination and search tasks based on triangular and circular elements (Triangle/Circle, observers AG, RK; Triangle-in-Circles, Circle-in-Triangles, observers JB, AG, RK) are shown in Figure $9 \mathrm{c}$.

Tasks involving patterned display elements (Fig. 9a,b) reproduced the outcome reported above: the letter task was executed with comparable success under separate and concurrent conditions. The three detection tasks were little affected by the 

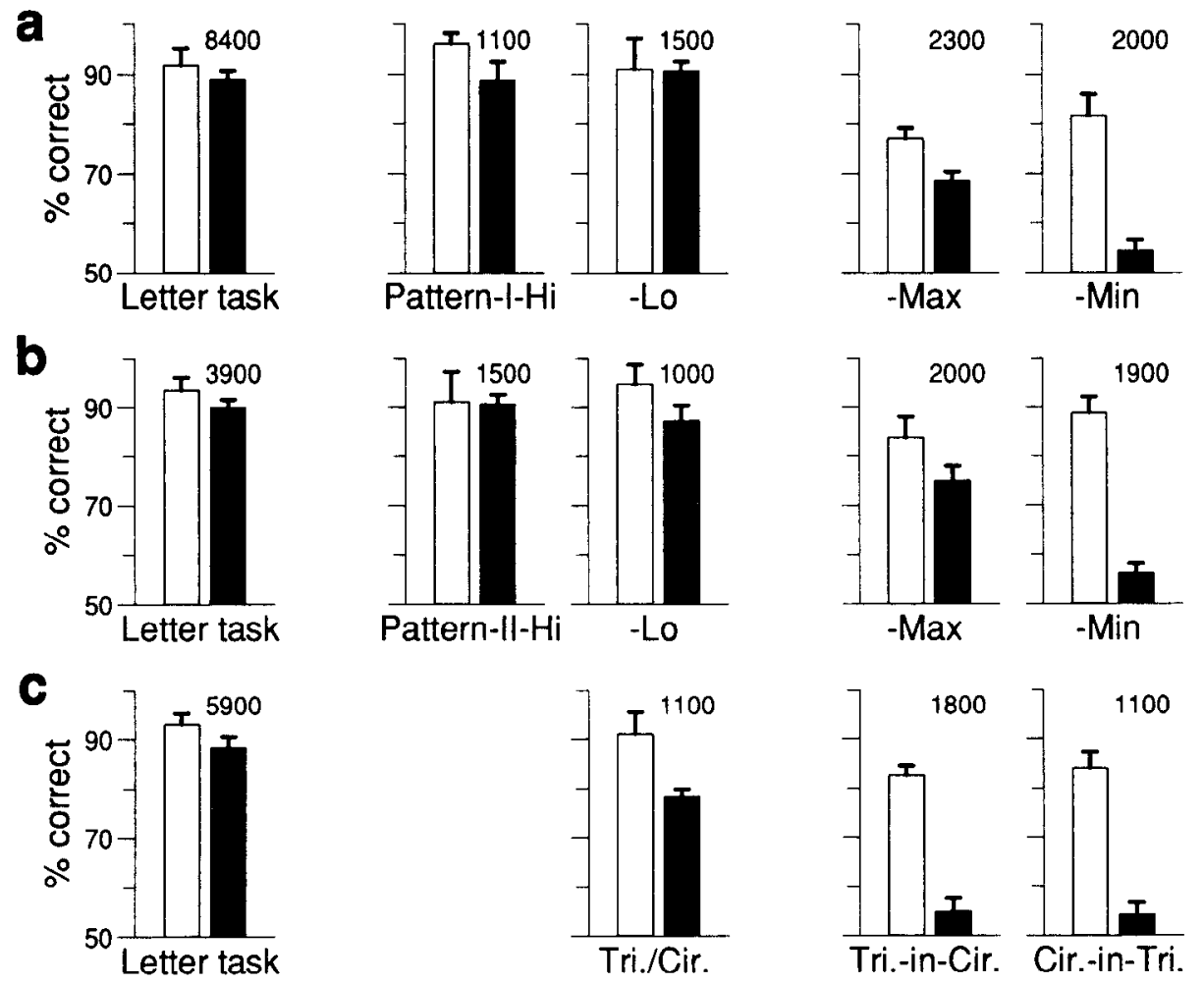

\section{Separate ( $\square$ ) and concurrent ( $\square$ ) performance}

Figure 9. Effect of concurrent letter task, continued (observer averages), $a$, search among, or detection of, display elements of coarse and intermediate pattern (Pattern-I-Hi, Pattern-I-LO, Pattern-I-Max, Pattern-I-Min); $b$, elements of intermediate and fine pattern (Pattern-II-Lo, -Max, -Min); $c$, elements of triangular and circular shape (Triangle/Circle, Triangle-in-Circles, Circle-in-Triangles). See Figure 8 caption for details. concurrent letter task. A substantial asymmetry was observed between Sfmax and Sfmin. Note that the search tasks in question included two search tasks employing identical distractor (and different target) items (Pattern-I-Max and Pattern-II-Min). The fact that dissimilar outcomes were obtained with these two search tasks (a small performance reduction with the former, and a large reduction with the latter) demonstrates that the outcome is not solely determined by the type of distractor item.

Only one group of tasks, those based on triangular and circular elements, exhibited a different pattern of results (Fig. $9 \mathrm{c}$ ). For both search tasks (Triangle-in-Circles and Circle-in-Triangles) concurrent performance remained near chance level, suggesting that successful performance of either task requires visual attention. This outcome was not due to insufficient discriminability of individual elements: in the absence of distractors, triangular and circular display elements proved discriminable even under concurrent task conditions (Triangle/Circle). Apparently, the presence of distractors (rather than the discriminability of individual elements) was the decisive factor.

The results concerning Sfmax and Sfmin can be summarized as follows (Table 2): concurrent execution of the letter task reduced performance of Sfmax and Sfmin by an average of 9.7 $\pm 5.0 \%$ and $26.8 \pm 6.0 \%$, respectively.

\section{Discussion}

\section{Search asymmetry}

The perceptual difficulty of a visual search can change dramatically when its target and distractor items are exchanged, a phe- nomenon that has been called "search asymmetry" (Treisman and Souther, 1985). For search asymmetry to occur, it appears to be necessary that target and distractor items are distinguished by one "critical" feature (Treisman, 1985; Treisman and Gormican, 1988). As an example, consider search among C- and O-shaped items (Treisman and Gormican, 1988; Williams and Julesz, 1991). Here, the critical feature is thought to be the open ends of the contour of the C. Search for a C-shaped item is generally easier than search for an O-shaped item although, individually, both types of items are equally detectable and thus would be considered equally salient. On the basis of findings of this type, Treisman and her collaborators have postulated that search asymmetry reflects the difference between search for the presence or absence of a critical feature (Treisman, 1985; Treisman and Southcr, 1985; Trcisman and Gormican, 1988).

Another type of search asymmetry is observed in texture segregation tasks, especially when a smaller region of one texture is embedded in a larger region of another texture (e.g., Guernsey and Browse, 1987). In this situation, search asymmetry appears to reflect the fact that the border between regions tends to be obscured by any discontinuities that may be present within regions, especially discontinuities within the larger region (Malik and Perona, 1990; Rubenstein and Sagi, 1990).

The present study concentrated on search tasks involving items that, individually, were differentially detectable against an empty background, and thus would be considered differentially salient. The intent was to limit the investigation to a set of identifiable situations, and to reproduce as closely as possible the search tasks investigated by Schiller and Lee (1991). 


\section{Balancing perceptual difficulty}

The difficulty of a visual task often depends on several factors. One factor is effective stimulus contrast, another is whether the task lends itself to a consistent decision criterion, and further factors enter when the task involves a limited resource of some kind, for example, visual attention, or memory (Green and Swets, 1966; Norman and Bobrow, 1975). Accordingly, if two tasks are performed equally well, it does not follow that they are equal with respect to any of these factors; for example, performance of one task may reflect low effective contrast, while performance of another may reflect its high demands on memory.

In the present study, the issue of perceptual difficulty arises because perceptual difficulty is one respect in which Sfmax and Sfmin differ (Julesz, 1981; Beck, 1982; Treisman, 1985). To determine whether there also exists a more fundamental difference, it was necessary to devise visual search tasks of comparable perceptual difficulty. To do so, the stimulus was varied (in a way that will be discussed presently) until the task was performed correctly in approximately $84 \%$ of the trials. Next, the two main factors determining perceptual difficulty-effective stimulus contrast and stability of decision criterion (Green and Swets, 1966)-were compared empirically. This was done by introducing a certain amount of stimulus noise and, separately, by reducing the stability of the decision criterion by a certain amount. Both manipulations turned out to have comparable effects on Sfmax and Sfmin. Thus, the effective stimulus contrast and stability of decision criterion appeared comparable, demonstrating that the investigated instances of Sfmax and Sfmin posed comparable perceptual difficulties.

Performance was adjusted by varying the delay between stimulus and mask, a procedure that resulted in an average criterion SOA of $98 \pm 13 \mathrm{msec}$ for Sfmax and $133 \pm 24 \mathrm{msec}$ for Sfmin. It appcars unlikcly that this procedure affected the involvement of visual attention. In other instances, the role of visual attention correlates with task type, not criterion SOA. For example, Gestalt grouping (Wertheimer, 1923; Koffka, 1935) depends on visual attention at a criterion SOA of $40 \mathrm{msec}$ ("easy" grouping, Ben-Av et al., 1992) as well as $150 \mathrm{msec}$ ("difficult" grouping, Braun and Bauer, 1993). Similarly, texture segregation (Julesz, 1981) does not require visual attention between criterion SOAs of $36 \mathrm{msec}$ (conspicuous texture border) and $>180 \mathrm{msec}$ (inconspicuous texture border) (Braun and Julesz, 1992; Braun and Julesz, unpublished observations). The case of texture segregation seems particularly relevant, as this type of visual task may well rely on similar mechanisms than Sfmax (see below).

\section{Removing visual attention}

In a concurrent task situation, an observer directs visual attention at one part of a display, leaving other parts unattended but, nevertheless, attempts to report attributes of both attended and unattended parts. This approach can be used to determine whether or not a particular visual task relies on visual attention (Kahneman, 1973; Braun and Sagi, 1990, 1991; Ben-Av et al., 1992). In the present report, visual attention was engaged by the letter task, which concerned a cluster of letter-shaped items near the center of the display. Successful execution of this task prevented the observer from attending to the target and distractors of the search task, which appeared in the periphery of the display. A quantitative assessment of the extent to which the letter task engages visual attention was reported elsewhere (Braun and Julesz, 1992; Braun and Julesz, unpublished observations). The main results were as follows.
The letter task is based on the discrimination of $T$ - and L-shaped elements, which is known to require visual attention (Bergen and Julesz, 1983; Kröse and Julesz, 1989). In fact, the letter task constitutes a visual search whose criterion SOA increases rapidly with element number. The degree to which performance of the letter task removes visual attention from the periphery of a display can be quantified with the help of a probe task. Using the discrimination of a singlc $\mathrm{T}$ or $\mathrm{L}$ as a probe task, the letter and probe tasks were found to be mutually exclusive: optimal performance on one task entailed chance performance on the other, and vice versa, implying that optimal performance engages visual attention completely. The length of time for which the letter task engages visual attention can also be quantified. When the appearance of the probe was delayed by $90 \mathrm{msec}$, probe performance recovered from chance to approximately $25 \%$ of normal. A delay of $180 \mathrm{msec}$ brought probe performance to approximately $50 \%$ of normal. Accordingly, performance of the letter task appeared to render visual attention essentially unavailable for roughly $90 \mathrm{msec}$, and approximately $25 \%$ available for roughly another $90 \mathrm{msec}$.

\section{Effect on Sfmax and Sfmin}

Removing visual attention by requiring observers to carry out the letter task concurrently proved to have markedly different effects on Sfmax and Sfmin (see Table 2). While Sfmax was only moderately affected-performance decreased on average by $9.8 \pm 5.0 \%-$ Sfmin was severely impaired-performance fell on average by $26.8 \pm 6.0 \%$ correct. In fact, concurrent performance of Sfmax remained relatively reliable at $74.4 \pm 3.7 \%$ correct, whereas performance of Sfmin approached chance level at $58.0 \pm 5.2 \%$ correct.

There were indications that it was the relative salience of target and distractors, not the absolute salience of either target or distractors, that determined the effect of removing visual attention. Whenever two tasks involved the same target but either more or less salient distractors, opposite outcomes were obtained (e.g., Size-Min and Size-Lo, or Pattern-I-Min and Pattern-II-Hi). In the one instance in which two tasks employed identical distractors but different targets, opposite outcomes were obtained as well (Pattern-I-Max and Pattern-II-Min).

The small but nevertheless significant performance reduction suffered by Sfmax in the absence of visual attention admits two explanations. Perhaps Sfmax was not entirely independent of visual attention. Another possibility is that the decision criterion was more stable in the presence of attention but that stimulus discriminability was the same. This would explain why more experienced observers experienced a smaller performance loss (compare Fig. $7 a, c$ and Fig. 8a,c).

That performance of Sfmin remaincd above chance even in the absence of visual attention also admits two explanations. Perhaps the stimulus remained somewhat discriminable even without attention. More likely, the residual discriminability reflected a residual availability of visual attention. Note that $\mathrm{Sfmin}$ was carried out, on average, at longer SOAs and therefore might have benefited from the $25 \%$ availability of visual attention after roughly $90 \mathrm{msec}$ (see above). Thus, stimulus discriminability might have been exactly zero had visual attention been entirely absent.

Unlike other instances of Sfmin, Color saturation-Min was performed well above chance level even without attention. Perhaps observers did not approach this task as an Sfmin, but rather as a search for a neutral hue. This interpretation would be con- 
sistent with the observation that hue discrimination can be independent of visual attention (Braun and Julesz, 1992).

Two instances of search among items of identical salience were investigated (Triangle-in-Circles, Circle-in-Triangles). Both tasks proved essentially impossible when visual attention was removed. Interestingly, the discrimination of a single triangular or circular item (in the absence of distractors) continued to be performed reliably. Apparently, the discriminability of triangular and circular shapes was independent of visual attention as long as the display did not contain distractors.

\section{Two functional systems?}

The results presented so far are most naturally understood by assuming that Sfmax and Sfmin are fundamentally different types of visual tasks and that their execution relies on distinct functional systems.

The functional system implicated in Sfmin is visual attention. Tasks that require allocation of visual attention include, besides Sfmin, shape discriminations such as the letter task (Braun and Julesz, 1992; Braun and Julesz, unpublished observations) and Gestalt grouping (Ben-Av et al., 1992; Braun and Bauer, 1993). If one speculates what these tasks might have in common, a disruptive background appears to be part of the answer. In Sfmin, the target is obscured by distractors of greater salience. In shape discrimination, the distinguishing features are usually hidden among many irrelevant ones. In Gestalt grouping, each element can usually be grouped in several ways, only one of which conforms to the overall perceptual organization.

A similar role of visual attention was inferred from the effect of lesions thought to disrupt visual attention. After lesions to the superior colliculus or pulvinar of macaque monkeys, target discrimination in the affected part of the field of view was impaired only when the unaffected part of the visual field contained a distractor (Desimone et al., 1989, 1990a). In other words, the presumed disruption of visual attention made itself felt only in the presence of distractors. Perhaps Sfmin, which is characterized by the presence of salient distractors, represents the paradigmatic situation requiring allocation of visual attention.

The functional system implicated in Sfmax are the mechanisms that process visual texture (Julesz, 1981, 1984). These mechanisms register local differences with respect to a number of stimulus dimensions (e.g., orientation, spatial frequency, color) (Malik and Perona, 1990; Rubenstein and Sagi, 1990; Sagi, 1990; Nothdurft, 1991) and do not require allocation of visual attention (Braun and Sagi, 1990, 1991; Ben-Av et al., 1992; Braun and Julesz, 1992; Braun and Julesz, unpublished observations). Although the perceptual role of these mechanisms remains unclear, it has been suggested that textural discontinuities provide a provisional segmentation of the field of view (Julesz, 1981; Beck et al., 1983). Another suggestion is that the representation of textural discontinuities may constitute a "saliency map" (Koch and Ullman, 1985) or "master map" (Treisman, 1988) that can guide visual orienting (eye movements, shifts of selective visual attention).

Filter-based, computational models account quite well for human performance on detecting textural discontinuities (Malik and Perona, 1990; Rubenstein and Sagi, 1990). If Sfmax involves the same mechanisms as detecting a textural discontinuity, then these computational models should also account for human performance on Sfmax. They should fail, however, to account for $S f \min$, since this type of search appears to rely on altogether different mechanisms.
The proposal advanced here-visual attention and the processing of visual texture as separate functional systems-is conventional in many respects. For example, it is consistent with the view that information about "where" is computed separately from information about "what" (Ungerleider and Mishkin, 1982; Sagi and Julesz, 1985). However, the proposal departs from the received view in one respect: rather than the usual succession of preattentive and attentive processing (Treisman and Gelade, 1980; Julesz, 1981; Duncan and Humphreys, 1989; Nakayama, 1990; Crick and Koch, 1990), it postulates that nonattentive and attentive processing occur side by side. For example, when an observer reports concurrently on attended and unattended objects, it is clear that some objects reach visual awareness independently of visual attention. In recognizing that visual awareness can be dissociated from visual attention, the proposal implies a more restrictive view of the perceptual role(s) of visual attention, and a more expansive view of the role(s) of mechanisms that are independent of attention.

\section{Effect of a lesion in area $V 4$}

Extrastriate area V4 occupies an intermediate place in the occipitotemporal cortical pathway (Maunsell and Newsome, 1987; Desimone and Ungerleider, 1989; Van Essen et al., 1992), and represents stimulus propertics, such as form and color, important for object recognition (Zeki, 1980; de Monasterio and Schein, 1982; Tanaka et al., 1986; Desimone and Schein, 1987; Schein and Desimone, 1990; Gallant et al., 1993). Neural activity in area V4 is modulated by visual attention (Fischer and Boch, 1981; Moran and Desimone, 1985; Mountcastle et al., 1987; Spitzer et al., 1988) and by expectancy with respect to future stimuli (Haenny and Schiller, 1988; Haenny et al., 1988; Maunsell et al., 1991).

Several groups have lesioned area V4 and assessed the consequences with behavioral tests. Some tests involved discrimination of wavelength or hue (Wild et al., 1985), while others probed a wide range of functions (Heywood and Cowey, 1987; Desimone et al., 1990b; Schiller and Logothetis, 1990; Weber and Fischer, 1990). From this work, it appears that lesions in area V4 impair the perception of both color and form, while having relatively little effect on the perception of binocular disparity and motion (Schiller and Logothetis, 1990).

An apparently unrelated pattern of deficits was revealed when the effect of a lesion in area V4 was assessed by means of Sfmax and Sfmin (Schiller and Lee, 1991). Although the salience of the items to be searched was varied in several ways (difference in size, contrast, hue saturation, velocity of motion, binocular disparity), the effect of the lesion appeared to be determined simply by the relative salience of target and distractor items: Sfmax was only moderately affected by the lesion while Sfmin was severely impaired.

The present work was motivated in part by the results of Schiller and Lee (1991) and employed comparable stimuli. In particular, comparable instances of visual search among items of different size, contrast, color saturation, pattern, and shape were used in both studies. In spite of the considerable difference in methodology - surgical lesion versus the psychophysical manipulation of imposing a concurrent task - the two studies produced qualitatively identical results.

\section{Two anatomical systems?}

Schiller and Lee (1991) interpreted their results cautiously, pointing out the different computational nature of Sfmax and 
Sfmin, and suggesting that "basic, reflexlike" mechanisms might be sufficient for the former, while "areas V1, V2, V4, and the temporal lobe" might be required for the latter. The present results reinforce this suggestion by raising the possibility that the lesion disrupted visual attention but spared the nonattentive processing of visual texture.

What further observations could confirm that visual attention and the proccssing of visual texture rely on separate anatomical systems? Clearly, a lesion in area V4 would have to affect tasks that resemble neither Sfmin nor Sfmax in proportion to the extent to which they require allocation of visual attention. For example, the lesion would have to disrupt Gestalt grouping (Ben-Av et al., 1992; Braun and Bauer, 1993) and spare texture segregation tasks (Braun and Sagi, 1990, 1991; Braun and Julesz, 1992). Finally, it is conceivable that a lesion in cortical or subcortical structures other than area V4 would exhibit the opposite effect and impair $S f$ max more severely than $S f$ min.

\section{References}

Beck J (1982) Textural segmentation. In: Organization and representation in perception (Beck J, ed), pp 285-317. Hillsdale, NJ: Erlbaum.

Beck J, Prazdny K, Rosenfeld A (1983) A theory of textural segmentation. In: Human and machine vision (Beck J, Hope B, Rosenfeld A, eds), pp 1-38. New York: Academic.

Ben-Av MB, Sagi D, Braun J (1992) Visual attention and perceptual grouping. Percept Psychophysics 52:277-294.

Bergen JR, Julesz B (1983) Parallel versus serial processing in rapid pattern discrimination. Nature 303:696-698.

Braun J, Bauer HU (1993) Attentive processing of two overlapping Glass patterns. Invest Ophthalmol Vis Sci [Suppl] 34:1236.

Braun J, Julesz B (1992) Early vision: dichotomous or continuous? Paper presented at 33d annual meeting of the Psychonomic Society, St. Louis, MO, November.

Braun J, Sagi D (1990) Vision outside the focus of attention. Percept Psychophysics 48:45-58.

Braun J, Sagi D (1991) Texture-based tasks are little affected by a second task which requires peripheral or central attentive fixation. Perception 20:483-500.

Cave KR, Wolfe JM (1990) Modeling the role of parallel processing in visual search. Cognit Psychol 22:225-271.

Colby CL (1991) The neuroanatomy and neurophysiology of attention. J Child Neurol 6:S90-S118.

Coltheart M (1980) Iconic memory and visible persistence. Percept Psychophysics 27:183-228.

Crick F, Koch C (1990) Some reflections on visual awareness. Cold Spring Harbor Symp Quant Biol 55:953-962.

de Monasterio FM, Schein SJ (1982) Spectral handwidths of color opponent cells of the geniculostriate pathway of macaque monkey. J Neurophysiol 47:214-224.

Desimone R, Schein SJ (1987) Visual properties of neurons in area V4 of the macaque: sensitivity to stimulus form. J Neurophysiol 57: $835-868$.

Desimone R, Ungerleider L (1989) Neural mechanisms of visual processing in monkeys. In: Handbook of neuropsychology, Vol 2 (Boller F, Grafman J, eds), pp 267-299. New York: Elsevier.

Desimone R, Wessinger M, Thomas L, Schneider W (1989) Effects of deactivation of lateral pulvinar or superior colliculus on the ability to selectively attend to a visual stimulus. Soc Neurosci Abstr 15:162.

Desimone R, Wessinger M. Thomas L, Schneider W (1990a) Attentional control of visual perception: cortical and subcortical mechanisms. Cold Spring Harbor Symp Quant Biol 55:963-971.

Desimone R, Li L, Lehky S, Ungerleider LG, Mishkin M (1990b) Effects of V4 lesion on visual discrimination and on responses of neurons in inferior temporal cortex. Soc Neurosci Abstr 16:621.

Duncan J, Humphreys GW (1989) Visual search and stimulus similarity. Psychol Rev 96:433-458.

Fischer B, Boch R (1981) Enhanced activation of neurons in prelunate cortex before visually guided saccades of trained rhesus monkeys. Exp Brain Res 44:129-137.

Gallant JL, Braun J, Van Essen DC (1993) Selectivity for polar, hy- perbolic, and cartesian gratings in macaque extrastriate visual cortex. Science 259:100-103.

Green DM, Luce RD (1975) Parallel psychometric functions from a sct of independent detectors. Psychol Rev 82:483-486.

Green DM, Swets JA (1966) Signal detectability and psychophysics. New York: Wiley.

Guernsey R, Browse RA (1987) Micropattern properties and presentation condition influencing visual texture discrimination. Percept Psychophysics 41:239-252.

Haenny PE, Schiller PH (1988) State dependent activity in monkey visual cortex. I. Single cell activity in V1 and V4 on visual tasks. Exp Brain Res 69:225-244.

Haenny PE, Maunsell JHR, Schiller PH (1988) State dependent activity in monkey visual cortex. II. Retinal and extraretinal factors in V4. Exp Brain Res 69:245-259.

Heilmann KM, Watson R'T, Valenstein E, Goldberg ME (1990) Attention: behavior and neural mechanisms. In: Handbook of physiology, V, The nervous system, Chap 11 (Brookhart JM, Mountcastle VB, eds), pp 461-481. Bethesda, MD: American Physiological Society.

Helmholtz H (1850) Physiological optics, Vol 3 (Southall JPC, ed, trans). Reprint. New York: Dover, 1925.

Heywond CA, Cowey A (1987) On the role of cortical area V4 in the discrimination of hue and pattern in macaque monkeys. J Neurosci 7:2601-2617.

James W (1890) The principles of psychology. Reprint. Cambridge, MA: Harvard UP.

Julesz B (1981) Textons, the elements of texture perception and their interactions. Nature 290:91-97.

Julesz B (1984) Towards an axiomatic theory of preattentive vision. In: Dynamic aspects of neocortical function (Edelman GM, Gall WE, Cowan WM, eds), pp 585-612. Bethesda, MD: Neurosciences Research Foundation.

Kahnemann D (1973) Attention and effort. Englewood Cliffs, NJ: Prentice Hall.

Kinchla RA (1992) Attention. Annu Rev Psychol 43:711-742.

Koch C, Ullman S (1985) Shifts in selective visual attention: towards the underlying neural circuitry. Hum Neurobiol 4:219-227.

Koffka K (1935) Principles of gestalt psychology. New York: Harcourt Brace.

Kröse B, Julesz B (1989) The control and speed of shifts of attention. Vision Res 29:1607-1619.

Malik J, Perona P (1990) Preattentive texture discrimination with early vision mechanisms. J Opt Soc Am [A] 7:923-932.

Maunsell JHR, Newsome WT (1987) Visual processing in monkey extrastriate cortex. Annu Rev Neurosci 10:363-401.

Maunsell JHR, Sclar G, Nealy TA, De Priest DD (1991) Extraretinal representations in area V4 in the macaque monkey. Vis Neurosci 7:561-573.

Moran J, Desimone R (1985) Selective attention gates visual processing in the extrastriate cortex. Science 229:782-784.

Mountcastle VB, Motter BC, Steinmetz MA, Sestokas AK (1987) Common and differential effects of attentive fixation on the excitability of parietal and prestriate (V4) cortical visual ncurons in the macaque monkey. J Neurosci 7:2239-2255.

Nachmias J (1981) On the psychometric function for contrast detection. Vision Res 21:995-1004.

Nakayama K (1990) The iconic bottleneck and the tenuous link between early visual processing and perception. In: Vision, coding and efficiency (Blakemore C, ed), pp 411-422. Cambridge: Cambridge UP.

Nakayama K, Silverman GH (1986) Serial and parallel processing of visual feature conjunctions. Nature 320:264-265.

Neisser U (1967) Cognitive psychology. New York: Appleton-Century-Crofts.

Norman DA, Bobrow DG (1975) On data-limited and resource-limited processes. Cognit Psychol 7:44-64.

Nothdurft HC (1991) Texture segmentation and pop-out from orientation contrast. Vision Res 31:1073-1078

Posner MI, Driver J (1992) The neurobiology of selective attention. Curr Opin Neurobiol 2:165-169.

Posner MI, Petersen SE (1990) The attention system of the human brain. Annu Rev Neurosci 13:25-42.

Rubenstein BS, Sagi D (1990) Spatial variability as a limiting factor 
in texture discrimination tasks: implications for performance asymmetries. J Opt Soc Am [A] 7:1632-1643.

Sagi D (1990) Detection of an orientation singularity in Gabor textures: effect of signal density and spatial frequency. Vision Res 30:13771385.

Sagi D, Julesz B (1985) "Where" and "what" in vision. Science 228: $1217-1219$.

Schein SJ, Desimone R (1990) Spectral properties of V4 neurons in the macaque. J Neurosci 10:3369-3389.

Schiller PH, Lee K (1991) The role of primate extrastriate area V4 in vision. Science 251:1251-1253.

Schiller PH, Logothetis NK (1990) The color-opponent and broadband channels of the primate visual system. Trends Neurosci 13:392398.

Schiller PH, Sandell JH, Maunsell JIIR (1986) Functions of the ON and OFF channels of the visual system. Nature 322:824-825.

Schiller PH, Logothetis NK, Charles ER (1990a) Role of the coloropponent and broad-band channels in vision. Vis Neurosci 5:321346.

Schiller PH, Logothetis NK, Charles ER (1990b) Functions of the color-opponent and broad-band channels of the visual system. Nature 343:68-70.

Schneider W, Shiffrin RM (1977) Controlled and automatic human information processing: I. Detection, search, and attention. Psycho Rev 84:1-66.

Sperling G, Dosher B (1986) Strategy and optimization in human information processing. In: Handbook of perception and performance, Vol I, Chap 2 (Boff K, Kaufman L, Thomas J, eds), pp 1-65. New York: Wiley.

Sperling G, Melchner MJ (1978) The attention operating characteristic: some examples from visual search. Science 202:315-318.

Spitzer H, Desimone R, Moran J (1988) Increased attention enhances both behavioral and neuronal performance. Science 240:338-340.

Tanaka M, Weber H, Creutzfeld OD (1986) Visual properties and spatial distribution of neurones in the visual association area on the prelunate gyrus of the awake monkey. Exp Brain Res 65:11-37.
Treisman A (1985) Preattentive processing in vision. Comput Vis Graph Imag Proc 31:156-177.

Treisman A (1988) Features and objects: the fourteenth Bartlett memorial lecture. Q J Exp Psychol 40A:201-237.

Treisman A, Gelade G (1980) A feature integration theory of attention. Cognit Psychol 12:97-136.

Treisman A, Gormican S (1988) Feature analysis in early vision: evidence from search asymmetries. Psychol Rev 95:15-48.

Treisman A, Souther J (1985) Search asymmetry: a diagnostic for preattentive processing of separable features. J Exp Psychol [Gen] $114: 285-310$.

Ungerleider LG, Mishkin M (1982) Two cortical visual systems. In: Analysis of visual behavior (Ingle DG, Goodale MAA, Mansfield RJW, eds), pp 549-586. Cambridge, MA: MIT Press.

Van Essen DC, Anderson CH, Felleman DJ (1992) Information processing in the primate visual system: an integrated systems perspective. Science 255:419-423.

Weber H, Fischer B (1990) Effect of a local ibotenic acid lesion in the visual association area on the prelunate gyrus (area V4) on saccadic reaction times in trained rhesus monkeys. Exp Brain Res 81:134 139.

Weibull WA (1951) A statistical distribution function of wide applicability. J Appl Mech 18:292-297.

Wertheimer M (1923) Untersuchungen zur Lehre von der Gestalt. Psychologische Forschung 4:301-350.

Wild HM, Butler SR, Carden D, Kulikowski JJ (1985) Primate cortical area V4 important for color constancy but not wavelength discrimination. Nature 313:133-135.

Williams DW, Julcsz B (1991) Filters versus textons in human and machine texture discrimination. In: Neural networks for human and machine perception (Wechsler H, ed), pp 201-203. Orlando, FL: Academic.

Zeki SM (1980) The representation of colors in the cerebral cortex. Nature 284:412-418. 